\title{
O desafio teórico-metodológico nas pesquisas de recepção
}

\author{
Roseli Fígaro ${ }^{1}$ \\ Universidade de São Paulo \\ figaro@uol.com.br
}

\begin{abstract}
Resumo: Este artigo tem o objetivo de apresentar e discutir a proposta teórico-metodológica adotada na pesquisa de recepção realizada, entre 2002-2004, em duas grandes empresas da Capital paulista. Essa pesquisa de recepção combinou métodos quantitativos e qualitativos e estudou a recepção da comunicação tendo como lugar de mediação o mundo do trabalho. $O$ artigo esclarece quais os pressupostos teóricos da pesquisa e busca demonstrar como a combinação de métodos atende à complexidade do processo comunicacional. Ou seja, discute a importância de se ampliar a análise da recepção para além de um ou de outro produto cultural específico, e se considerar o estudo do processo comunicacional a partir do ponto de vista do receptor.
\end{abstract}

Résumé: Cet article a l'objectif pour présenter et discuter la proposition théorique et méthodologique adopté en une recherche de reception réalisé, entre 2002-2004, dans deux grandes entreprises a ville de São Paulo. Cette recherche de reception a combinée des méthodes quantitatives et qualitatives et a étudié la reception de la comunication ayant comme lieu de médiation le monde du travail. L'article clarifie quel sont les présupposes théoriques de la recherche et démontre comme la combinaison de méthodes correspond à la complexité du processus comunicacional. Il discute l'importance de s'amplifier l'analyse de la réception pour au delà d' un ou d'un autre produit culturel spécifique et besoin de considerer l'étude du processus comunicacional du point de vue du réceptor.

Abstract: This article has aims to present and to debate the theoritical and methodological proposal applied in reception research carried out, between 2002-2004, in two big companies in the São Paulo city. This reception research combined quantitative and qualitative methods and studied the reception of the communication having the world of the work as mediation place. The article clarifies the theoretical presuppositions of the research and searchs to demonstrate as the combination of methods takes care of the complexity of the comunicacional process. Moreover, it argues the importance of extending the reception analysis beyond of one or

\footnotetext{
${ }^{1}$ Jornalista, professora doutora do Departamento de Comunicações e Artes da Escola de Comunicações e Artes da USP. Coordenadora do projeto de Pesquisa Comunicação e Trabalho, com apoio da Fapesp.
} 
another specific cultural product and considering the study of the comunicacional process from receptor point of view (perspective).

Resumen: Este artículo tiene el objetivo de presentar y discutir la propuesta teorico- metodologica adoptada en pesquisa efectuada, entre 2002-2004, en dos grandes empresas de la capítal de São Paulo. Esta pesquisa de recepción ha combinado métodos cuantitativos y cualitativos y estudió la recepción de la comunicación teniendo como lugar de mediación el mundo del trabajo. El artículo esclarece cuáles las presuposiciónones teóricas de la investigación y busca demonstrar como la combinación de métodos atiende a la complejidad del proceso comunicacional. $O$ sea, discute la importancia de ampliarse la análisis de la recepción para además del un u otro producto cultural específico, es necesario el estudio del proceso comunicacional a partir del punto de vista de lo receptor.

Palavras-chave: estudo de recepção, metodologia, mundo do trabalho.

Mots-clé: étude de réception, méthodologie, monde du travail.

Key-words: study of reception, methodology, world of the work.

Palabras clave: estudio de recepción, metodología, mundo del trabajo.

Os Estudos de Recepção ganharam importância no Brasil e em toda a América Latina. Para isso foram importantes as contribuições dos Estudos Culturais na tradição de Williams, Hogart, Hall e Thompson, pois permitiram que o campo da comunicação retomasse a problemática do sujeito. Os estudos e pesquisas de recepção também buscaram fundamentos na análise do discurso, na história das mentalidades e na antropologia, para propor uma abordagem diferenciada às problemáticas tradicionais relativas à comunicação. Jesús Martín-Barbero, Guillermo Orozco Gómes e Néstor García Clanclini têm sido importantes para dar vazão a uma série de pesquisas as quais se ramificam num amplo espectro de outras afiliações teóricometodológicas.

Desde a publicação de Comunicação e Trabalho. Estudo de Recepção: o mundo do trabalho como mediação da comunicação, em 2001, temos dado continuidade à pesquisa de recepção que tem o mundo do trabalho como o locus central da problemática teórico-metodológica de investigação. Os 
métodos quantitativos e qualitativos de pesquisa têm dado sustentação a uma prática metodológica que combina diversificadas técnicas com a intenção de apurar os resultados obtidos na investigação.

Com o objetivo de consolidar tal proposta teórico-metodológica, realizamos, no período de 2002-2004, pesquisa de recepção, com apoio da Fapesp, em duas grandes empresas de tecnologia de comunicação na Capital paulista - Siemens e BCP/Claro. Para essa pesquisa, estabelecemos ainda os objetivos de analisar quais os sentidos que os receptores empregados das empresas pesquisadas dão ao trabalho; e observar como o universo do trabalho contribui para que a recepção se configure na construção desses sentidos.

\section{Aspectos teóricos da pesquisa}

Do ponto de vista teórico, adotamos como conceitos básicos a concepção de comunicação como processo mediado pelas práticas culturais que se constroem no cotidiano, permeadas pelas relações de classes, as quais se dão num momento em que o capitalismo encontra-se sob orientação do capital financeiro, com fluxos globalizados e oligopolizados. O movimento de hegemonia e contra-hegemonia (Gramsci,1978) orienta a dialética que se estabelece em nossa observação do processo de comunicação.

Partindo dessa concepção, o conceito de mediação foi trabalhado como "ambiente" permeado por um conjunto de relações que implica em práticas cotidianas que perpassam, afirmam, reorientam ou transformam os processos de comunicação. Ao ser adotado neste sentido, o conceito de mediação permite-nos devolver aos sujeitos receptores, nos estudos ou pesquisas de recepção, a complexidade que lhes é inerente.Tomamos, assim, como fator decisivo de estudo o lugar de vida, de ação, de atividade do sujeito receptor. Fato que nos possibilita revelar as relações sociais e os processos comunicacionais que fazem parte do cotidiano desse sujeito. 
Estudar a recepção a partir da mediação do mundo do trabalho significa recortar tal universo e problematizá-lo tendo em vista as transformações objetivas afeitas a este universo, ou seja, introdução de novas tecnologias e processos de trabalho, bem como novos métodos de gestão de pessoas e estratégias de logística. Significa também trazer para o campo da Comunicação conceitos tais como: trabalho, produção linear, produção flexível, relações de produção, entre outros, mais comuns ao campo da Sociologia do trabalho. Ao adotarmos o mundo do trabalho como mediação a partir da qual se estuda a recepção, os conceitos acima explicitados foram tratados tendo em vista o campo da Comunicação, mantendo-se a coerência de entendê-los na dialética das relações de classe do sistema de capitalismo tardio, conforme define Jameson (1996).

A escolha deste referencial teórico levou-nos ainda a nos deparar com os trabalhos de J. Habermas (1999), especificamente com os conceitos de ação comunicativa e razão comunicativa. Habermas, ao formulá-los, privilegiou as relações comunicativas como forças potenciais na construção do consenso para viabilizar a utopia de uma sociedade guiada pela razão. $\mathrm{O}$ autor adotou tal posição, fazendo longa discussão filosófica - teoria do conhecimento - e sociológica - teoria social, a partir da qual firmou a posição de primazia da comunicação no desenvolvimento da sociedade humana. Fez tal afirmação para confrontar a concepção marxista do materialismo histórico, cujos conceitos centrais são trabalho e relações de produção.

Habermas consubstanciou o privilégio da comunicação em detrimento do trabalho, explicando a fundamental importância da linguagem verbal e da atividade discursiva no desenvolvimento da organização racional da sociedade humana, afirmando inclusive que a teoria dos atos de fala guardaria em si uma teoria da comunicação.

Nossas pesquisas têm mostrado uma realidade diferente da expressa pelos conceitos de Habermas. O estudo dos processos de produção, aqueles 
advindos das transformações incorporadas ao universo do trabalho, demonstra como a comunicação passou a ser ainda mais fundamental no mundo do trabalho. A comunicação incorporou-se ao mundo do trabalho, em diferentes aspectos: como ferramenta, tecnologia, informação, gestão de processos, persuasão, discursos de gestão de pessoas, treinamentos, etc., fazendo parte, dessa forma, das forças produtivas ${ }^{2}$. E, assim sendo, a categoria trabalho permanece fundamental para se compreender a sociedade contemporânea. Entender profundamente essa questão significa problematizar as mudanças que se deram nas últimas décadas e percebê-las como mudanças principalmente no âmbito das transformações no mundo do trabalho com a incorporação, em todos as etapas e processos, do conceito comunicacional. Portanto, linguagem e trabalho são aspectos fundantes das relações humanas. É difícil estabelecer a primazia de um sobre o outro. Mas, se adotássemos a primazia da linguagem verbal como sistema intrínseco à racionalidade da organização social, acabaríamos por estabelecer um sinal de igualdade entre realidade e representação (significação) e daríamos primazia à fala, ao discurso, em detrimento do seu contexto. Finalmente, acabaríamos por afirmar que a linguagem verbal é que dá sentido à relação entre sujeitos em um contexto específico, e não o contrário, o que considero real, o contexto de relação entre sujeitos é que dá sentido ao uso da linguagem verbal. Quando referimo-nos ao contexto da relação entre sujeitos estamos nos referindo à

\footnotetext{
${ }^{2}$ Forças produtivas (verbete) "Forças naturais (inclusive o próprio homem) apropriadas pelo homem para a produção e reprodução de sua vida social. A parte material das forças produtivas, isto é, os instrumentos de trabalho e os objetos de trabalho, constituem a base material e técnica da sociedade. A principal força produtiva, no entanto, é o próprio homem, que cria instrumentos de trabalho cada vez mais poderosos, aperfeiçoa seus objetos de trabalho, combina ambos no sentido de ampliar constantemente a produção. Isso significa que as forças produtivas tendem a crescer constantemente. Essa expansão opera modificações nas relações de produção e no modo de produção. Assim, a determinado nível de desenvolvimento das forças produtivas correspondem determinadas relações de produção. De acordo com Marx, ' (...) o que distingue as épocas econômicas não é o que se produz, mas como se produz, isto é, com que instrumentos de trabalho se produz. Os instrumentos de trabalho não são apenas o barômetro indicador do desenvolvimento da força de trabalho do homem, mas também o expoente das condições sociais em que se produz.'(...) ". Cf. Dicionário de Economia. Os Economistas. São Paulo: Nova Cultural,1985. p. 175.
} 
base dessas relações, ou seja, as atividades que ligam os homens e permitem que sobrevivam.

Nos últimos anos, tem sido bastante recorrente a utilização dos conceitos habermasianos na ideação de políticas de comunicação corporativa. Já salientamos anteriormente:

\begin{abstract}
"Alguns teóricos têm proposto que, para se entender a comunicação e para a apropriação da comunicação pela lógica empresarial, devem-se utilizar esses dois conceitos, de ação comunicativa e de razão comunicativa, como busca de consenso e como fundamento teórico para a implantação da base discursivoideológica que está na organização dos processos de gestão do trabalho, conforme discutimos. Como se a linguagem verbal e a comunicação verbal tivessem por si, enquanto sistema de signos, poder de racionalizar as relações entre sujeitos. Tomam a linguagem como instrumento. Esquecem que a linguagem é parte intrínseca da realidade social, manifestando toda a complexidade das relações sociais (...)" (Figaro, 2005: 113).
\end{abstract}

A linguagem verbal e a comunicação não constroem apenas o consenso, elas revelam os conflitos. Não é a construção de uma estratégia discursiva que altera a realidade. É a realidade que altera o discurso3.

O estudo da recepção, tendo o mundo do trabalho como mediação, permitiu-nos ver os conflitos vivenciados pelos trabalhadores e a luta deles para tentarem compreender o que de fato ocorre. Os estudos de recepção nos revelam um cotidiano repleto de aspirações contraditórias, cujo referencial importante ainda são os colegas de trabalho. Aspirações que também conformam o processo de recepção das mídias. Sejam os veículos de comunicação da corporação ou os meios de comunicação de massa.

São os dados conseguidos pela pesquisa empírica que confirmam nossos pressupostos teóricos.

\footnotetext{
3 Esta discussão mereceu maior atenção em nosso artigo: Recepção no mundo do trabalho: uma crítica à ação comunicativa, 2002.
} 


\section{Aspectos metodológicos da pesquisa}

Do ponto de vista metodológico, uma pesquisa como essa - que toma a comunicação de um lugar social, o mundo do trabalho, ou seja, do locus onde se dá a construção dos sentidos - propõe uma reflexão sobre as práticas metodológicas adotadas pelos estudos de recepção, e destaca, como já foi dito, a pertinência do cruzamento de procedimentos quantitativos e qualitativos de investigação. $\mathrm{O}$ cruzamento desses métodos deve-se à necessidade de se consolidar uma metodologia de pesquisa que dê maior respaldo aos estudos de recepção, muitas vezes fundamentados em métodos e técnicas de pesquisa que não tratam de maneira extensiva, profunda e consistente o objeto empírico foco da investigação.

Adotamos o método quantitativo para tratarmos a amostra empírica, composta por representatividade social e numérica, recortada do universo de trabalhadores das empresas Siemens e $\mathrm{BCP} /$ Claro. Aplicamos à amostra um questionário com questões de múltipla escolha, para obter dados sobre o perfil socioeconômico, escolaridade, sexo, faixa etária, faixa salarial, histórico pessoal e profissional; e, em maior número, questões relativas aos hábitos de consumo cultural, lazer e sociabilidade.

A tabulação dos questionários deu-nos a possibilidade de construirmos o que denominamos de mapas de hábitos de consumo cultural dos trabalhadores. Ressalte-se que os entrevistados são trabalhadores regulamente contratados pelas empresas, têm escolaridade do nível médio à pós-graduação. Foram entrevistados trabalhadores de todos os níveis funcionais, exceto cargos de direção. A análise desses mapas levou-nos a firmar posições balizadas por dados mais objetivos, os quais, por exemplo, nos permitem fazer afirmações como as que seguem:

a) há um grande nivelamento entre as opções culturais nos diferentes níveis econômicos e de escolaridade; 
b) entre os diferentes níveis de escolaridade, a leitura de veículos de comunicação impressos é pequena; chama atenção o quanto ela é de fato pouco realizada entre os níveis de escolaridade mais altos;

c) entre os níveis de escolaridade mais altos a televisão também permanece como o veículo de comunicação de acesso mais freqüente;

d) a internet é um veículo de acesso a todos os entrevistados, principalmente como instrumento de trabalho;

e) apesar de grande parte dos entrevistados ter acesso a internet várias vezes ao dia, ela ainda não é vista como uma importante fonte de informação para o dia-a-dia dos entrevistados;

f) o acesso a TV por assinatura ainda é expressivamente restrito às camadas de maior salário e nível de escolaridade;

g) chama atenção o fato de ser maior o acesso a internet do que o acesso a TV por assinatura entre os entrevistados (isto é possível graças ao acesso a internet no local de trabalho);

h) entre os sexos, aparece como expressiva a diferença entre a opção de leitura e assistência à televisão, contrariamente ao que se esperava, as mulheres lêem mais do que os homens e assistem menos à TV do que os homens;

i) a televisão é o veículo de maior importância ou pelo menos de maior presença no cotidiano dos entrevistados;

j) segue em importância a TV, as relações interpessoais no ambiente de trabalho com os colegas;

l) mesmo os entrevistados de maior poder aquisitivo afirmaram fazer opções no seu dia-a-dia que relegam o cinema, o teatro, a leitura de livros e mesmo de jornais e revistas para escalões inferiores à TV aberta e à internet; 
m) a leitura dos boletins e jornais da empresa, embora seja feita pela maioria absoluta dos entrevistados, não é destacada quando se trata de eleger as principais fontes de informação para o dia-a-dia;

n) a imprensa sindical é quase completamente ausente das leituras dos entrevistados e não aparece em nenhum momento entre as primeiras fontes de informação de importância para o dia-a-dia dos entrevistados;

o) chama atenção o fato de a faixa salarial e o nível socioeconômico, não determinarem necessariamente o acesso a jornais, revistas, cinema e, principalmente, a teatro. $\mathrm{O}$ hábito de acesso aos bens culturais precisa ser criado, a par das possibilidades econômicas que permitem o acesso a eles;

p) vale destacar que, apesar de haver uma certa padronização das opções de consumo cultural, é clara a especificidade e a variedade da hierarquização de importância das opções por níveis socioeconômicos;

r) os dados revelam que as escolhas dos produtos culturais giram em torno dos pontos de vista hegemonicamente consolidados. Nem mesmo publicações como Carta Capital, Caros Amigos e boletins sindicais estão na preferência dos entrevistados. Mesmo assim, a especificidade das interpretações, como dito acima, é garantida pela diferente hierarquização de importância dada às opções de acesso aos meios de comunicação.

Outro fato que a pesquisa revela, é o quanto do tempo das pessoas é dedicado à empresa, inclusive nos mais altos cargos. Há pequena participação em instituições como igreja, academia de ginástica, instituições de caridade, grupos de teatro, coral etc... A vida dos entrevistados se dá no espaço do trabalho, da casa e, para alguns, da escola. As relações com os colegas de trabalho são privilegiadas, à medida que são raros outros grupos de amizade, não há tempo disponível para isso. O tempo fora do trabalho é o tempo da família e/ou do namorado(a), ou ainda da escola (no caso dos mais jovens). Confirma-se, mais uma vez, a importância dos colegas de trabalho no processo de recepção. Eles são fonte de informação privilegiada pelos entrevistados, 
mais do que os veículos de comunicação da empresa e até mesmo da internet, pois constituem seus laços de sociabilidade.

Tais afirmações constituíram-se em balizas para continuarmos e aprofundarmos as investigações.

A partir dos resultados disponíveis nos mapas de hábitos de consumo cultural, adotamos dois outros métodos qualitativos de investigação. $\mathrm{O}$ primeiro adotou a técnica da entrevista em profundidade aplicada a um recorte da amostra inicial, perfazendo $10 \%$ de entrevistados proporcionalmente aos diferentes níveis socioeconômicos da amostra. As entrevistas foram realizadas a partir de um roteiro de perguntas abertas, o qual tinha por objetivo recolher a narrativa do entrevistado sobre sua história de vida no trabalho e suas opções de consumo cultural.

Todas as entrevistas foram transcritas na íntegra e foram analisados os discursos. A análise do discurso foi fundamentada nos conceitos de dialogismo e polifonia de M. Bakhtin (1988).

A segunda técnica adotada foi a de análise dos veículos de comunicação de maior presença no cotidiano dos entrevistados. Os mapas de consumo cultural permitiram que fizéssemos um levantamento dos gêneros e dos veículos de comunicação mais citados pelos entrevistados. Selecionamos, a partir de um recorte temático e temporal, as matérias jornalísticas e a programação de rádio e TV de maior preferência dos entrevistados. Todo esse material foi analisado buscando-se compreender os sentidos que o discurso enunciado creditava aos temas trabalho, desemprego e violência. Cabe ressaltar que estes temas foram os repetidamente citados como os de maior interesse para os trabalhadores entrevistados.

Ainda para tratar dos veículos de comunicação de maior interesse para os entrevistados, analisamos a comunicação corporativa das empresas da pesquisa. Selecionamos publicações dirigidas ao conjunto dos trabalhadores, publicadas ao longo de 2002 e 2003. Todo o material foi analisado tendo em 
vista forma e conteúdo. A análise do discurso foi o método aplicado para estudar as matérias. Da análise, chamou nossa atenção o vocabulário utilizado na produção dos textos. São palavras comuns utilizadas com sentidos particulares ao universo de trabalho, fortemente identificado com métodos de gestão de pessoas, pertinentes à reestruturação produtiva e à produção flexível. Temos como parte deste vocabulário de novo sentido, palavras como, por exemplo,: colaborador, utilizada para substituir a palavra empregado; cliente para nomear a relação entre empregados de um setor que têm relações de trabalho com empregados de outro setor da mesma empresa; qualidade, utilizada no sentido de economia de recursos e tempo de trabalho; corte, usada no sentido de aproveitamento máximo dos recursos disponíveis, inclusive da mão de obra; entre muitas outros vocábulos. Estrangeirismo são bastante comuns e fazem parte do jargão utilizado para se referirem aos modelos de gestão de pessoas e processos de trabalho.

Além desse novo vocabulário, pudemos constatar a lógica da persuasão como aspecto da estratégia da elaboração do texto e da edição dos veículos de comunicação. Pudemos verificar ainda a interdiscursividade que se apresenta entre a modalidade do discurso jornalístico e do discurso publicitário, cunhando quase que uma nova modalidade discursiva com características delineadas.

A entrevista em profundidade, com os receptores em seus locais de trabalho, revelou-nos um discurso matizado pelo orgulho de ser escolhido para trabalhar na empresa e ao mesmo tempo preocupado com o futuro, com o que mais se terá que fazer para continuar na empresa na dinâmica incessante de mudanças, cortes de custos e de cargos. O trabalho é a maneira de ganhar a vida e a empresa é a materialização dessa possibilidade para uns, mas para outros, principalmente os de menor salário, o trabalho e a empresa significam a própria continuidade de vida. Por outro lado, a preocupação com o futuro no trabalho, faz com que o discurso seja perpassado por um sentido 
de dor, sofrimento. Para alguns, a solidão é parte da escolha feita por permanecer na empresa e no tipo de trabalho. Uma fatalidade à qual se precisa adaptar. Para outros, o fantasma do desemprego e da permanente crise do mercado de trabalho são fatores de inconformidade, mas de difícil solução. Solução não visualizada pela maioria. A crise do mundo do trabalho é enunciada pelos receptores como uma fatalidade que deve ser suportada e, na medida do possível, esquivar-se dela para manter-se na ativa. Aqueles que conseguem elaborar, um ou dois dos entrevistados, de maneira mais clara e objetiva, uma explicação para a situação que se vive e sobre o acerto dos rumos tomados vão buscar as bases de seus discursos nos compêndios teóricos dos cursos de especialização em diferentes instituições universitárias. O discurso da empresa e de sua comunicação não supre tal necessidade e nem se propõe a tanto, como se não existisse qualquer possibilidade ou questionamento sobre alterações dos rumos econômicos das grandes corporações e da economia mundial.

Estes e muitos outros resultados estão relatados no Relatório dos Resultados da Pesquisa Comunicação e Trabalho, Fapesp, São Paulo, 2004.

Finalmente, cabe destacar, primeiro, que uma pesquisa desse vulto demanda grande infra-estrutura tanto de equipamentos quanto de mão-deobra; segundo, que ela nos permite compreender de maneira mais clara a circularidade dos sentidos e a apropriação que os diferentes grupos sociais fazem desses sentidos; terceiro, permite-nos comprovar a importância teórica das mediações no mundo do trabalho, pois é a partir de um lugar concreto, ou seja, de um contexto, que se constrói a inter-relação entre receptores hierarquias, poder, veículos, tecnologias, linguagens - para a construção dos sentidos e, portanto, da comunicação; quarto, a riqueza do material empírico permitirá que outros estudos possam ser feitos a partir dele; quinto, e último, a proposta metodológica para o Estudo de Recepção aqui delineada é um desafio, mas mostrou-se absolutamente possível de ser executada e de ser 
provada como condição para que estes estudos tenham maior respaldo científico.

\section{Bibliografia}

ANTUNES, Ricardo. Os sentidos do trabalho. São Paulo: Boitempo, 2000. Adeus ao trabalho? Ensaios sobre as metamorfoses e a centralidade do mundo do trabalho. 3. ed. São Paulo: Cortez/Edunicamp, 1995 .

ARAGÃO, Lucia M. de C. Razão comunicativa e teoria social crítica em Jürgen Habermas. Rio de Janeiro: Tempo brasileiro, 1997.

BACCEGA, Maria A. Comunicação e linguagem. Discursos e ciência. São Paulo: Moderna, 1998.

BAKHTIN, Mikhail. Marxismo e filosofia da linguagem. São Paulo: Hucitec, 1988.

BECKER, Howard S. Métodos de pesquisa em Ciências Sociais. São Paulo: Hucitec, 1994.

BRANDÃO, Helena H. Nagamine. Introdução à Análise do Discurso. Campinas: Unicamp, 1991.

DICIONÁRIO DE ECONOMIA. Os Economistas. São Paulo: Nova Cultural,1985. p. 175

FAIRCLOUGH, Norman. Discurso e mudança social. Brasília: UnB, 2001. FÍGARO PAULINO, Roseli A. Comunicação e Trabalho. Estudo de recepção: o mundo do trabalho como mediação da comunicação. São Paulo: Anita/Fapesp, 2001.

. Recepção da comunicação no mundo do trabalho: uma crítica à ação comunicativa. Ciberlegenda. Revista do programa de pós-graduação em comunicação da Universidade Federal Fluminense. n. 9, 2002. ISSN 15190617.

. (org.) Gestão da comunicação. No mundo do trabalho, educação, terceiro setor e cooperativismo. São Paulo: Atlas, 2005.

GRAMSCI, Antônio. Obras escolhidas. São Paulo: Martins Fontes, 1978.

GARCIA CANCLINI, Néstor. Consumidores e cidadãos. Conflitos multiculturais da globalização. Rio de Janeiro: UFRJ, 1995.

Culturas híbridas. estrategias para entrar y salir de la modernidad. México, D.F.: Grijalbo, 1990. 
HABERMAS, J. Toría de la acción comunicativa (I e II).Buenos Aires: Taurus, 1999.

. Consciência moral e agir comunicativo. Rio de Janeiro:

Tempo Brasileiro, 1989.

HALL, Stuart. Da diáspora. Identidade e mediações culturais. SOVIK, Liv (org.).Belo Horizonte/Brasília: UFMG/Hitas/Unesco, 2003.

HOGART, Richard. Utilizações da cultura: aspectos da vida da classe trabalhadora. Lisboa: Presença, 1973.

JAMSON, Fredric. Pós-modernismo. A lógica cultural do capitalismo tardio. São Paulo: Ática, 1996.

JENSEN, K.B., JANKOWSKI, N.W. (eds.) Metodologias cualitativas de investigación en comunicación de masas. Barcelona: Bosch, 1993.

LOJKINE, J. A classe operária em mutações. Belo Horizonte: Oficina de Livros, 1990.

LOPES, Maria Immacolata V. de . Pesquisa em comunicação. 4.ed. São

Paulo: Loyola, 1999.

MARTÍN-BARBERO, Jesús. De los medios a las mediaciones. 3. ed.

México: G. Gilli, 1993.

MORAES, Dênis. (org.) Globalização, mídia e cultura contemporânea.

São Paulo: Letra Livre, 1997.

OROZCO-GÓMEZ, Guillermo. (org.) Televidencia. Perspectivas para el análisis de los procesos de recepción televisiva. Cuadernos de

comunicación y practicas sociales. México: Universidad Iberoamericana, n. 6,1994 .

. La comunicación desde las practicas sociales. Reflexiones en torno a su investigación. Cuadernos de comunicación y prácticas sociales. México: Universidad Iberoamericana, n.1, 1990.

. Medios, audiencias y mediaciones. Comunicar. Revista de Educacion en Medios de Comunicación. Andalucia: Grupo Comunica, n. 8, mar. 1997.

PÊCHEUX, Michel. Semântica e discurso - Uma crítica à afirmação do óbvio. Campinas: Edunicamp, 1988.

. O discurso. Estrutura ou acontecimento. Campinas: Pontes, 1990.

THOMPSON, E. P. Tradición, revuelta y consciencia de classes.

Estudios sobre la crisis de la sociedad preindustrial. 2.ed. [s.n.] 1984.

SCHAFF, Adam. Linguagem e conhecimento. Coimbra: Almedina, 1976.

WILLIAMS, Raymond. Cultura. Rio de Janeiro: Paz e Terra, 1992. 
Península, 1974.

. Los medios de comunicación social. 2.ed. Barcelona:

1969.

Cultura e sociedade 1780-1950. São Paulo: Nacional, 